\title{
Prevention of periprosthetic joint infection: Pre-, intra-, and post-operative strategies
}

\author{
A Shahi MD \\ J Parvizi MD, FRCS
}

Rothman Institute at Thomas Jefferson University, Philadelphia, PA

\author{
Corresponding author: \\ Javad Parvizi MD, FRCS \\ $125 \mathrm{~S}$ 9th Street \\ Philadelphia, PA 19107 \\ Tel: (267) 339-3605 \\ Fax: (215) 503-5651 \\ Email: parvj@aol.com
}

\begin{abstract}
Prosthetic joint infection (PJI) is a calamitous complication with high morbidity and substantial cost. The reported incidence is low but it is probably underestimated due to the difficulty in diagnosis. PJI has challenged the orthopaedic community for several years and despite all the advances in this field, it is still a real concern with immense impact on patients and the healthcare system. Numerous factors can predispose patients to PJI. In this review we have summarised the effective prevention strategies along with the recommendations of a recent International Consensus Meeting on Surgical Site and Periprosthetic Joint Infection.
\end{abstract}

Key words: PJI, prevention, infection, total hip replacement, total knee replacement, total joint arthroplasty

\section{Introduction}

Total joint arthroplasty (TJA) is the ultimate treatment for degenerative joint disease. It restores function in the majority of patients and improves quality of life. It is projected that by the year 2030 the total number of primary total knee arthroplasty (TKA) procedures in the United States will reach 3.48 million per year, a $673 \%$ increase in comparison with the number of procedures in 2005. Furthermore, the demand for total hip arthroplasty (THA) is projected to grow by $174 \%$, which would be 572000 procedures per year. That is about 4 million TJAs per year.

Similar to all medical interventions, TJA is accompanied by some complications, the most challenging of which is periprosthetic joint infection (PJI). Infection is the leading cause of revision after TKA and the third most common reason for revision THA in the Medicare population. ${ }^{2-5} \mathrm{PJI}$ can occur any time after the surgery, and there is no 'gold standard' for diagnosis. ${ }^{6-8}$ PJI has a huge financial impact on the healthcare system. Revision due to infection cost about $\$ 320$ million in 2001 , increased to $\$ 566$ million in 2009 , and is projected to exceed $\$ 1.62$ billion by 2020 in the United States. ${ }^{9}$ Prevention of PJI is therefore imperative.

\section{Definition of PJI}

Until recently there was no unified definition for PJI. In 2011, in an effort to standardise the definition of PJI, a list of criteria was provided by the Musculoskeletal Infection Society (MSIS). ${ }^{10}$

In addition, in August 2013, the International Consensus Meeting (ICM) on PJI was held in Philadelphia. More than 400 experts from 52 countries and representatives from over 130 societies convened. The ICM supported the MSIS definition of PJI and modified it by adding a minor criterion (leukocyte esterase test) and determining the threshold for lab results. ${ }^{11}$

According to the modified definition, a definite PJI is present when:

- There is a sinus tract communicating with the prosthesis, OR

- A phenotypically identical pathogen is isolated by culture from two or more separate tissue or fluid samples obtained from the affected prosthetic joint, OR the third most common reason for revision THA 
- When three of the following five criteria exist:

1. Elevated serum erythrocyte sedimentation rate AND serum C-reactive protein concentration

2. Elevated synovial white blood cell count, OR ++ change on leukocyte esterase test strip

3. Elevated synovial polymorphonuclear percentage

4. Positive histological analysis of periprosthetic tissue

5. A single positive culture.

Note that PJI can exist regardless of the absence of these criteria in some cases, such as low-virulence microorganisms like Propionibacterium acnes.

\section{Classifications of PJI}

Based on the pathogenesis or the timing of the clinical manifestation, different classifications are suggested for PJI. As far as pathogenesis is concerned, PJI is either exogenous or haematogenous. ${ }^{12}$

PJI can occur any time post-operatively. Based on the time interval between the surgery and the onset of the clinical manifestations, PJI can be divided into four different stages: ${ }^{12-14}$

1. Stage one/early: symptoms start within the first 4 to 8 weeks post-operatively.

2. Stage two/delayed: presents 3 to 24 months after the surgery.

3. Stage three/late onset: usually occurs after 2 years postoperatively.

4. Stage four/silent PJI: a condition in which a positive culture is captured at the time of revision in a patient with no symptom of infection.

Early, delayed and silent infections are often exogenous. Early PJI is usually caused by virulent organisms such as $S$. aureus. Late PJI has an acute clinical manifestation and is usually haematogenous. Silent PJI is mostly caused by lowvirulence microorganisms such as coagulase-negative staphylococci or Propionbacterium acnes. ${ }^{14,15}$ The most common sources of contamination are the patient's skin and soft tissue. Nevertheless, some studies reported seeding from the respiratory, urinary and gastrointestinal tracts, and dental infections. ${ }^{16}$ Sendi et al. ${ }^{17}$ reported that in $57.5 \%$ of haematogenous PJI, there was no sign of primary bacteraemia or infection during the clinical manifestation; therefore, it is usually difficult to identify the source of infection.

\section{Prevention of PJI}

Many different factors are involved in the development of PJI. These elements concern both the host and the environment. Conditions that can increase the risk of infection include (but are not limited to): uncontrolled diabetes, rheumatoid arthritis, renal failure, congestive heart failure, hypercholesterolaemia, malnutrition, pulmonary disease, valvular heart disease, pre-operative anaemia, venous thromboembolism, peripheral vascular disease, metastatic tumour, psychosis, alcohol abuse and depression. ${ }^{3,18-20}$
Patients who undergo elective arthroplasty are typically in suboptimal health. Additionally, the impact of various risk factors is cumulative. . $^{21,22}$ Therefore, it is imperative to identify the risk factors and address them pre-operatively to reduce the risk of PJI and other post-operative complications.

Generally strategies to prevent PJI are categorised as preoperative, intra-operative and post-operative.

\section{Pre-operative period}

\section{Medical optimisation of host}

All modifiable conditions should be optimised prior to an elective TJA. Studies have shown that the patient's general health has a direct link with post-operative complications. An American Society of Anesthesiologists score of greater than 2, uncontrolled diabetes, and rheumatoid arthritis, for example, can significantly increase the risk of PJI. ${ }^{18,20,23-25}$ Furthermore, any other comorbidity accompanied by diabetes is shown to place patients at a cumulatively higher risk for infection. ${ }^{21,26}$

Merchant et al..$^{27}$ reported that patients with a higher level of haemoglobin A1c are at a higher risk of PJI, with an odds ratio of 2.31. Additionally, not only is the pre-operative glucose level an important factor, but Mraovic et al. ${ }^{28}$ demonstrated that the post-operative blood glucose level also plays an important role as far as the risk for PJI is concerned. The authors stated that patients with sugar levels of greater than $200 \mathrm{mg} / \mathrm{dl}$ on post-operative day 1 were twice more likely to develop PJI. Therefore, evaluating patients in a multidisciplinary clinic prior to performing TJA is crucial in order to identify comorbidities and manage them, if required. These assessments significantly reduce post-operative mortality and pre-admission costs in complex orthopaedic surgeries, including TJA. ${ }^{29}$

\section{The ICM comment}

The ICM workgroup stated that certain conditions such as history of previous surgery, uncontrolled diabetes mellitus (glucose levels $>200 \mathrm{mg} / \mathrm{L}$ or $\mathrm{HbA} 1 \mathrm{C}>7 \%$ ), malnutrition, morbid obesity (body mass index $>40 \mathrm{~kg} / \mathrm{m}^{2}$ ), chronic renal disease, active liver disease, excessive smoking ( $>$ one pack per day), exorbitant alcohol use ( $>40$ units per week), intravenous drug abuse, extended stay in a rehabilitation facility, recent hospitalisation, post-traumatic arthritis, inflammatory arthropathy, previous surgical procedure in the affected joint, male gender, and severe immunodeficiency can increase the risk of developing PJI..$^{30}$

\section{Bacterial decolonisation (pre-operative skin cleansing)}

Prevention guidelines regarding surgical site infections (SSI) published by the Centers for Disease Control (CDC) recommended patients take a bath with an antiseptic agent at least once on the night before the operation to reduce the load of bacteria. ${ }^{31}$ 
Many reports have shown that a whole-body bath with an antiseptic agent reduces the bacterial load in the skin and lowers the risk of developing SSI. ${ }^{32-35}$ According to the CDC, SSIs are the second most common cause of nosocomial infections and are responsible for more than $25 \%$ of hospital-related infections in the United States. ${ }^{36,27}$ There is still a debate on how to achieve entire-body coverage and maintain adequate concentrations of the solution for effective results. Another issue is the patient's compliance with these protocols. ${ }^{38}$

\section{The ICM comment}

The ICM group suggests that a whole-body skin cleansing regimen with chlorhexidine gluconate $(\mathrm{CHG})$ should begin at least one night before the surgery. In case of sensitivity to CHG or when it is not available, antiseptic soap can also be used. ${ }^{39}$

\section{Prophylactic antibiotics}

It is believed that prophylactic antibiotics are one of the most important factors in preventing PJI. ${ }^{40-43}$ One of the sentinel studies in the field of orthopaedic surgery is that of Fogelberg et al. ${ }^{40}$, in 1970. They compared two groups of patients; one group was given prophylactic penicillin preoperatively, intra-operatively, and up to 5 days postoperatively; and the other group was not given any antibiotics. The incidence of infection was $1.7 \%$ the group receiving antibiotics versus $8.9 \%$ in the group that did not receive antibiotics. The study also demonstrated that methicillin-resistant Staphylococcus aureus (MRSA) infections were increased in the antibiotic group, demonstrating the fine balance between appropriate use of antibiotics and its overuse.

The American Association of Orthopaedic Surgeons (AAOS) published a guideline discussing the choice and dosing of prophylactic antibiotics. ${ }^{22}$ The optimum time for prophylactic antibiotic administration is within an hour prior to the surgery, in order to reach the minimal inhibitory concentration in the end organs during the operation. ${ }^{44}$ In certain conditions such as prolonged surgical duration beyond the half-life of the antibiotic or when excessive blood loss occurs during the surgery, a second dose of antibiotic is required.

\section{Indications for vancomycin}

First-generation cephalosporins are adequate for the majority of patients undergoing elective TJA. In some circumstances, however, administration of vancomycin or a teicoplanin is also indicated. Currently the use of vancomycin or teicoplanin is deemed to be appropriate in:

- patients who are carriers of MRSA

- patients from dialysis units or centres with an outbreak of MRSA

- healthcare workers

- patients who are allergic to penicillin.

\section{The ICM comment}

A first- or second-generation cephalosporin (cefazolin or cefuroxime) is suggested as routine pre-operative surgical prophylaxis, administered within an hour prior to the surgical incision. The timing can be extended up to two hours for vancomycin and fluoroquinolones. No special considerations are required for patients with pre-existing prostheses such as heart valves, and the same antibiotics can be used. ${ }^{45}$

\section{Intra-operative}

\section{Hair removal}

Hair removal at the incision site has become a part of the routine patient preparation for surgery. Interestingly, there is no evidence to support the role of hair removal in reducing the risk of SSI. A review article by the Cochrane group stated that there is no statistical difference in the incidence of SSI when hair, at the surgical site, is removed versus when it is not. The article mentioned that patients whose hair was removed using a razor had even higher rates of infection compared to those on whom clippers were used. ${ }^{46}$

\section{The ICM comment}

The consensus group suggested the hair removal be attempted as close to surgery as possible and done with the use of clippers. The ICM group had no comment on the use of depilatory cream for hair removal. ${ }^{39}$

\section{Pre-operative skin preparation}

\section{Patients}

One of the most common causes of SSI are the native microorganisms of the skin..$^{47,48}$ In a study by von Eiff $e t$ al.$^{49}$ it was shown that in more than $80 \%$ of nosocomial infections with Staphylococcus aureus, the source of the infection was endogenous, based on the genotyping evaluations.

According to the CDC's estimation, SSI is the second major cause for nosocomial infections, and is responsible for more than one-fourth of the hospital-related infections in the United States. ${ }^{37}$ Hence, despite new advances in prophylactic antibiotics, skin-decolonising agents still have crucial importance. Various antiseptic agents are available for surgical skin preparation. The most common ones are: $\mathrm{CHG}$, alcohol-based solutions, and povidone-iodine, all of which have advantages and disadvantages. $\mathrm{CHG}$, for instance, is very popular due to its long-lasting and cumulative effect against Gram-positive and Gram-negative bacteria. Povidone-iodine is very effective on skin flora; however, it becomes relatively ineffective upon contact with blood and has a shorter duration of activity in comparison with $\mathrm{CHG}^{36}$ 
Alcohol is a very good antimicrobial agent but the flammability and discontinued effect after drying are the downsides. A meta-analysis by the Cochrane group in 2004 stated that there was no significant difference in the rate of SSI in clean surgeries carried out using different antiseptic agents. ${ }^{50}$ Recent studies mentioned that alcohol and CHG combination is more successful than alcohol and povidoneiodine in reducing the bacterial load of the skin; however, the rate of SSI was not significantly different. ${ }^{51-53}$

\section{The ICM comment}

The ICM workgroup stated that there is no superiority of one skin preparation agent over another. There is some evidence that combinations of antiseptic agents with alcohol may be helpful for skin antisepsis. ${ }^{39}$

\section{Surgeons}

Antiseptic hand preparation agents are categorised into two main groups: hand scrub and hand rub agents. Hand scrubs are usually solutions of CHG or povidone-iodine and hand rubs are mostly alcohol-based solutions. Most studies reported equivalent efficacy in decreasing bacterial colony units when comparing povidone-iodine with CHG. Furthermore, the incidence of SSI is not different using either hand scrub solutions or hand rubs. ${ }^{54,55}$ However, hand rubs require less water consumption and have better surgeon compliance. ${ }^{54}$

\section{The ICM comment}

The surgeon and other operating room (OR) personnel should wash their hands with an antiseptic agent for at least two minutes prior to the first case. The ICM group stated no preference for one antiseptic agent over others. ${ }^{39}$

\section{Draping}

There is a strong support in the literature for the use of plastic adhesive tapes for draping the surgical site. Numerous studies have shown that the rate of SSI is significantly increased when traditional cloth drapes were used. ${ }^{56-60}$ In one study, plastic adhesive drapes were compared with cloth, and deep wound contamination rates were compared. Cultures were collected right before closing and the result showed $60 \%$ of contamination when cloth drapes were used versus $6 \%$ with plastic adhesive drapes. ${ }^{57}$ Ritter et al. ${ }^{61}$ presented that iodophor-incorporated drapes can reduce wound contamination but do not decrease the wound infection rate after TJA. Plastic adhesive drapes are effective when skin preparation is performed using alcohol-based solutions. DuraPrep (3M Company, St. Paul, MN) is believed to improve the adhesion properties of the drapes. ${ }^{62}$ However, there are controversies about the effectiveness of adhesive incise drapes for the prevention of bacterial contamination. In 2007 the Cochrane group reviewed about 3000 patients in five different studies and concluded that there is no evidence to support that the use of adhesive incise drapes (plain or infused with antimicrobials) can reduce the rate of SSI. ${ }^{63}$

\section{The ICM comment}

The ICM group identified studies that demonstrated iodineimpregnated skin incise drapes can decrease skin bacterial loads. However, they found no study that would be able to demonstrate a correlation between the use of iodine-impregnated drapes and the incidence of SSI. The ICM has no comment on the use of skin barriers and recommends further studies. ${ }^{64}$

\section{Surgical gloves}

Sterile surgical gloves are dual protection barriers; on one side the glove protects the patient from residual bacteria on the surgeon's hands, and on the other side it protects the surgeon from the patient's body fluids.

Double gloving reduces the risk of glove perforation; and in procedures such as orthopaedic surgeries, where sharp edges could be encountered easily, following double gloving protocols is highly recommended..$^{65-67}$ However, with a double gloving protocol, the inner glove could still be perforated and become contaminated during the course of the procedure. Therefore, some studies have shown that in procedures such as implantation, triple gloving is the protocol of choice..$^{68,69}$

\section{Following double gloving protocols is highly recommended}

Sutton et al..$^{70}$ introduced the triple gloving protocol in 1998. The authors used two latex gloves with a cut-resistant layer between them. Results showed a significant decrease in perforation compared with the double-gloving protocol. In a study by Pieper et al. ${ }^{71}$ different protocols of triple gloving were compared to double gloving in maxillofacial surgeries. The authors presented that various techniques of triple gloving are superior to double gloving in terms of protecting the inner glove from perforation. However, triple gloving has some disadvantages, such as decreased tactile sensation and surgeon dexterity.

\section{The ICM comment}

The ICM group suggested the use of double gloving. However, they recognised the theoretical advantages of triple gloving. ${ }^{64}$

\section{Antibiotics in cement}

There are many reports stating that adding antibiotics to cement can decrease the risk of PJI in THA. ${ }^{72,73}$ However, there is no consensus on the fact that it is an effective strategy for TKA or not. ${ }^{74,75}$

\section{The ICM comment}

The ICM group believes that antibiotic-impregnated polymethylmethacrylate cement can reduce the risk of PJI development and should be considered in patients at high risk for PJI following elective arthroplasty. ${ }^{76}$ 


\section{Blood conservation}

Allogeneic blood transfusion is an independent predictor for PJI, and the number of transfused units has a direct link with the likelihood of developing PJI. ${ }^{77}$ The latter statement can be justified with the modulating effects of transfusion on the immune system..$^{7}$ This fact endorses the importance of pre-operative patient optimisation. Correction of preexisting anaemia is one of the best ways to minimise the amount of intra-operative transfusion..$^{79}$ Other preventive strategies include meticulous haemostasis to minimise blood loss, neuraxial anaesthesia, and the use of tranexamic acid. ${ }^{80,81}$

\section{The ICM comment}

The ICM group believes that allogeneic blood transfusion can increase the risk of developing SSI and/or PJI. Furthermore, management of pre-operative anaemia with iron, with or without erythropoietin, can decrease the risk of intra-operative transfusion. The ICM group endorses neuraxial anaesthesia to reduce the amount of blood loss during TKA and THA. ${ }^{82}$

\section{The OR environment}

\section{Laminar airflow}

The ultimate goal of OR design is to diminish the patient's exposure to the infecting organisms throughout the procedure. To pursue this aim, laminar airflow was introduced in 1964. However, there are controversies on the efficacy of laminar flow in reducing SSIs. Some studies stated that laminar flow could even increase the risk of SSIs. ${ }^{83}$ The CDC has no comment regarding the use of laminar airflow in reducing SSI. Nevertheless, the CDC has released a guideline for the proper use of laminar airflow.

\section{The ICM comment}

The ICM group believes that arthroplasty may be performed in ORs that are not equipped with laminar flows. The ICM has no comment in favour or against the use of laminar flows and recommends further studies. ${ }^{64}$

\section{Duration of the operation}

The risk of PJI has a direct link with the duration of the operation. ${ }^{84,85}$ Furthermore, the surgeon's surgical volume also has a potential effect on the rate of SSI; surgeons with lower number of surgeries tend to have higher rates of infection. ${ }^{86}$

\section{The ICM comment}

The ICM workgroup believes that the rate of SSI has a direct link with the duration of the surgery. They recommend that a coordinated effort must be made to minimise the surgical duration without compromising the procedure. $^{64}$

\section{OR traffic}

The incidence of SSI is directly related to the OR traffic. OR traffic can increase the load of airborne microorganisms. Furthermore, more door openings due to higher traffic can interfere with laminar airflow, which can itself increase the rate of SSI. ${ }^{87-89}$

\section{The ICM comment}

The ICM recommended that OR traffic should be kept at a minimum. ${ }^{64}$

\section{Medical equipment}

Several studies have demonstrated that equipment contamination can occur during surgery ${ }^{90-94}$ Givissis et al. ${ }^{91}$ investigated the contamination rate of suction tips and tried to correlate it with the development of subsequent deep wound infection. The authors reported a $54 \%$ rate of contamination in the suction tips. One of the cases developed deep SSI with the same organism that was isolated from the suction tip. The authors concluded that the contamination rate has a direct link with operation time. Therefore, they recommended that the suction tip should be changed every hour in long orthopaedic procedures. Davis et al. ${ }^{90}$ determined the contamination rates of glove tips $(28.7 \%)$, syringe bags $(20.0 \%)$, gown swabs $(17.0 \%)$, base of light handles $(14.5 \%)$, body of light handles $(14.5 \%)$, sieve swabs (13.5), suction tips $(11.4 \%)$, needles for deep closure $(10.1 \%)$, skin blades $(9.4 \%)$, and inside blades $(3.2 \%)$. Beldame et al. ${ }^{95}$ reported significantly higher rates of contamination in gloves prior to prosthesis implantation and advised changing gloves before this step.

\section{The ICM comment}

The ICM workgroup recommended changing suction tips every 60 minutes. Suction tips can be inserted into the femoral canal to evacuate fluid but should not be left there, where significant amounts of ambient air and particles are circulated that can potentially contaminate the case. Furthermore, the workgroup encourages surgeons to change their gloves at least every 90 minutes and after cementation. The ICM recommended further study on electrocautery devices and had no specific comment on their use. ${ }^{64}$

\section{Post-operative}

\section{Prevention of late PJI}

PJI may occur any time after the surgery. Episodic bacteraemia can be a potential risk for PJI development. Certain medical procedures are more likely to cause bacteraemia. In 2012, the AAOS released a new guideline on 'The Prevention of Orthopaedic Implant Infections in Patients Undergoing Dental Procedures'. 
The guideline is a collaboration between the AAOS and the American Dental Association. It has three main recommendations: ${ }^{96}$

1. 'The practitioner might consider discontinuing the practice of routinely prescribing prophylactic antibiotics for patients with hip and knee prosthetic joint implants undergoing dental procedures.

2. We are unable to recommend for or against the use of topical oral antimicrobials in patients with prosthetic joint implants or other orthopaedic implants undergoing dental procedures.

3. In the absence of reliable evidence linking poor oral health to PJI, it is the opinion of the workgroup that patients with prosthetic joint implants or other orthopaedic implants maintain appropriate oral hygiene.'

\section{The ICM comment}

The ICM workgroup concluded that the use of prophylactic antibiotics prior to dental procedures in patients who have TJA in place should be based on the individual's risk factors and the complexity of the dental procedure.

Furthermore, in cases of viral infection, there is no role for oral antibiotics, even for patients at higher risk.

The workgroup also concluded that for other minor surgical procedures such as endoscopy and colonoscopy, transient bacteraemia could be minimised by administration of prophylactic antibiotics, especially in high-risk patients. ${ }^{97}$

\section{Conclusion}

PJI is a serious complication with a significant morbidity and mortality. Several factors in the pre-, intra-, and postoperative periods are involved that can predispose a patient to develop PJI. Prevention is always better than treatment. One of the most important pre-operative factors to reduce the risk of PJI is to optimise the patient's general health prior to elective arthroplasty. Evaluation of all patients in pre-assessment clinics prior to elective TJA is recommended. Pre-operative prophylactic antibiotic administration should always be considered. Implementation of a surgical safety checklist can significantly reduce the incidence of SSI and subsequent PJI. It is imperative to follow the recommendations of the CDC and the AAOS to minimise the risk of infection intraoperatively. Finally, patients who undergo TJA are always at risk of developing infection; therefore, it is essential to administer appropriate prophylactic antibiotics prior to certain medical procedures. Medical science is fluid in nature. Further research and developments may provide better insights for prevention of infection after orthopaedic procedures.

One of the most important pre-operative factors to reduce the risk of PJI is to optimise the patient's general health prior to elective arthroplasty

\section{References}

1. Kurtz S, Ong K, Lau E, Mowat F, Halpern M. Projections of primary and revision hip and knee arthroplasty in the United States from 2005 to 2030. J Bone Joint Surg Am 2007;89:780-5. doi:10.2106/JBJS.F.00222.

2. Bozic KJ, Kurtz SM, Lau E, Ong K, Chiu V, Vail TP, et al. The Epidemiology of Revision Total Knee Arthroplasty in the United States. Clin Orthop 2010;468:45-51. doi:10.1007/ s11999-009-0945-0.

3. Bozic KJ, Kurtz SM, Lau E, Ong K, Vail TP, Berry DJ. The epidemiology of revision total hip arthroplasty in the United States. J Bone Joint Surg Am 2009;91:128-33. doi:10.2106/JBJS.H.00155.

4. Clohisy JC, Calvert G, Tull F, McDonald D, Maloney WJ. Reasons for revision hip surgery: a retrospective review. Clin Orthop 2004:188-92.

5. Vessely MB, Whaley AL, Harmsen WS, Schleck CD, Berry DJ. The Chitranjan Ranawat Award: Long-term survivorship and failure modes of 1000 cemented condylar total knee arthroplasties. Clin Orthop 2006;452:28-34. doi:10.1097/01.blo.0000229356.81749.11.

6. Della Valle C, Parvizi J, Bauer TW, Dicesare PE, Evans RP, Segreti J, et al. Diagnosis of periprosthetic joint infections of the hip and knee. J Am Acad Orthop Surg 2010;18:760-70.

7. Parvizi J, Adeli B, Zmistowski B, Restrepo C, Greenwald AS. Management of periprosthetic joint infection: the current knowledge: AAOS exhibit selection. J Bone Joint Surg Am 2012;94:e104. doi:10.2106/JBJS.K.01417.

8. Della Valle C, Parvizi J, Bauer TW, DiCesare PE, Evans RP, Segreti J, et al. American Academy of Orthopaedic Surgeons clinical practice guideline on: the diagnosis of periprosthetic joint infections of the hip and knee. J Bone Joint Surg Am 2011;93:1355-7. doi:10.2106/JBJS.9314ebo.

9. Kurtz SM, Lau E, Watson H, Schmier JK, Parvizi J. Economic burden of periprosthetic joint infection in the United States. J Arthroplasty 2012;27:61-65.e1. doi:10.1016/ j.arth.2012.02.022.

10. Parvizi J, Zmistowski B, Berbari EF, Bauer TW, Springer BD, Della Valle CJ, et al. New definition for periprosthetic joint infection: from the Workgroup of the Musculoskeletal Infection Society. Clin Orthop 2011;469:2992-4. doi:10.1007/s11999-011-2102-9.

11. Proceedings of the International Consensus Meeting on Periprosthetic Joint Infection. Foreword. J Orthop Res Off Publ Orthop Res Soc 2014;32 Suppl 1:S2-3. doi:10.1002/jor.22543.

12. Zimmerli W, Trampuz A, Ochsner PE. Prosthetic-joint infections. N Engl J Med 2004;351:1645-54. doi:10.1056/ NEJMra040181.

13. Fitzgerald RH Jr, Nolan DR, Ilstrup DM, Van Scoy RE, Washington JA 2nd, Coventry MB. Deep wound sepsis following total hip arthroplasty. I Bone Joint Surg Am 1977;59:847-55.

14. Tsukayama DT, Estrada R, Gustilo RB. Infection after total hip arthroplasty. A study of the treatment of one hundred and six infections. J Bone Joint Surg Am 1996;78:512-23.

15. Zimmerli W, Moser C. Pathogenesis and treatment concepts of orthopaedic biofilm infections. FEMS Immunol Med Microbiol 2012;65:158-68. doi:10.1111/j.1574-695X.2012. 00938.x. 
16. Maderazo EG, Judson S, Pasternak H. Late infections of total joint prostheses. A review and recommendations for prevention. Clin Orthop 1988:131-42.

17. Sendi P, Banderet F, Graber P, Zimmerli W. Clinical comparison between exogenous and haematogenous periprosthetic joint infections caused by Staphylococcus aureus. Clin Microbiol Infect Off Publ Eur Soc Clin Microbio Infect Dis 2011;17:1098-100. doi:10.1111/j.14690691.2011.03510.x.

18. Pulido L, Ghanem E, Joshi A, Purtill JJ, Parvizi J. Periprosthetic joint infection: the incidence, timing, and predisposing factors. Clin Orthop 2008;466:1710-5. doi:10.1007/s11999-008-0209-4.

19. Garvin KL, Konigsberg BS. Infection following total knee arthroplasty: prevention and management. Instr Course Lect 2012;61:411-9.

20. Bozic KJ, Lau E, Kurtz S, Ong K, Berry DJ. Patient-related risk factors for postoperative mortality and periprosthetic joint infection in medicare patients undergoing TKA. Clin Orthop 2012;470:130-7. doi:10.1007/s11999-011-2043-3.

21. Malinzak RA, Ritter MA, Berend ME, Meding JB, Olberding EM, Davis KE. Morbidly obese, diabetic, younger, and unilateral joint arthroplasty patients have elevated total joint arthroplasty infection rates. J Arthroplasty 2009;24:84-8. doi:10.1016/j.arth.2009.05.016.

22. Fletcher $\mathrm{N}$, Sofianos D, Berkes MB, Obremskey WT. Prevention of perioperative infection. J Bone Joint Surg Am 2007;89:1605-18. doi:10.2106/JBJS.F.00901.

23. Buller LT, Sabry FY, Easton RW, Klika AK, Barsoum WK. The preoperative prediction of success following irrigation and debridement with polyethylene exchange for hip and knee prosthetic joint infections. J Arthroplasty 2012;27:857-864.e1-4. doi:10.1016/j.arth.2012.01.003.

24. Jämsen E, Huhtala H, Puolakka T, Moilanen T. Risk factors for infection after knee arthroplasty. A register-based analysis of 43,149 cases. J Bone Joint Surg Am 2009;91:38-47. doi:10.2106/JBJS.G.01686.

25. Jämsen E, Nevalainen P, Eskelinen A, Huotari K, Kalliovalkama J, Moilanen T. Obesity, diabetes, and preoperative hyperglycemia as predictors of periprosthetic joint infection: a single-center analysis of 7181 primary hip and knee replacements for osteoarthritis. J Bone Joint Surg Am 2012;94:e101. doi:10.2106/JBJS.J.01935.

26. Lai K, Bohm ER, Burnell C, Hedden DR. Presence of medical comorbidities in patients with infected primary hip or knee arthroplasties. J Arthroplasty 2007;22:651-6. doi:10.1016/j.arth.2006.09.002.

27. Marchant MH Jr, Viens NA, Cook C, Vail TP, Bolognesi MP. The impact of glycemic control and diabetes mellitus on perioperative outcomes after total joint arthroplasty. J Bone Joint Surg Am 2009;91:1621-9. doi:10.2106/JBJS.H.00116.

28. Mraovic B, Suh D, Jacovides C, Parvizi J. Perioperative hyperglycemia and postoperative infection after lower limb arthroplasty. J Diabetes Sci Technol 2011;5:412-8.

29. Kamal T, Conway RM, Littlejohn I, Ricketts D. The role of a multidisciplinary pre-assessment clinic in reducing mortality after complex orthopaedic surgery. Ann $\mathrm{R}$ Coll Surg Engl 2011;93:149-51. doi:10.1308/003588411X561026.

30. Aggarwal VK, Tischler EH, Lautenbach C, Williams GR, Abboud JA, Altena M, et al. Mitigation and Education. J Arthroplasty 2014;29:19-25. doi:10.1016/j.arth.2013.09.028.
31. Mangram AJ, Horan TC, Pearson ML, Silver LC, Jarvis WR. Guideline for Prevention of Surgical Site Infection, 1999. Centers for Disease Control and Prevention (CDC) Hospital Infection Control Practices Advisory Committee. Am J Infect Control 1999;27:97-132; quiz 133-134; discussion 96.

32. Rao N, Cannella B, Crossett LS, Yates AJ Jr, McGough R 3rd. A preoperative decolonization protocol for staphylococcus aureus prevents orthopaedic infections. Clin Orthop 2008;466:1343-8. doi:10.1007/s11999-008-0225-4.

33. Bleasdale SC, Trick WE, Gonzalez IM, Lyles RD, Hayden MK, Weinstein RA. Effectiveness of chlorhexidine bathing to reduce catheter-associated bloodstream infections in medical intensive care unit patients. Arch Intern Med 2007;167:2073-9. doi:10.1001/archinte.167.19.2073.

34. Climo MW, Sepkowitz KA, Zuccotti G, Fraser VJ, Warren DK, Perl TM, et al. The effect of daily bathing with chlorhexidine on the acquisition of methicillin-resistant Staphylococcus aureus, vancomycin-resistant Enterococcus, and healthcare-associated bloodstream infections: results of a quasi-experimental multicenter trial. Crit Care Med 2009;37:1858-65. doi:10.1097/CCM.0b013e31819ffe6d.

35. Rao N, Cannella BA, Crossett LS, Yates AJ Jr, McGough RL 3rd, Hamilton CW. Preoperative screening/decolonization for Staphylococcus aureus to prevent orthopedic surgical site infection: prospective cohort study with 2-year followup. J Arthroplasty 2011;26:1501-7. doi:10.1016/ j.arth.2011.03.014.

36. Darouiche RO, Wall MJ Jr, Itani KMF, Otterson MF, Webb AL, Carrick MM, et al. Chlorhexidine-Alcohol versus Povidone-Iodine for Surgical-Site Antisepsis. N Engl J Med 2010;362:18-26. doi:10.1056/NEJMoa0810988.

37. Hidron AI, Edwards JR, Patel J, Horan TC, Sievert DM, Pollock DA, et al. NHSN annual update: antimicrobialresistant pathogens associated with healthcare-associated infections: annual summary of data reported to the National Healthcare Safety Network at the Centers for Disease Control and Prevention, 2006-2007. Infect Control Hosp Epidemiol Off J Soc Hosp Epidemiol Am 2008;29:996-1011. doi:10.1086/591861.

38. Ramos N, Skeete F, Haas JP, Hutzler L, Slover J, Phillips M, et al. Surgical site infection prevention initiative - patient attitude and compliance. Bull NYU Hosp Jt Dis 2011;69:312-5.

39. Tokarski AT, Blaha D, Mont MA, Sancheti P, Cardona L, Cotacio GL, et al. Perioperative skin preparation. J Arthroplasty 2014;29:26-8. doi:10.1016/j.arth.2013.09.029.

40. Fogelberg EV, Zitzmann EK, Stinchfield FE. Prophylactic penicillin in orthopaedic surgery. J Bone Joint Surg Am 1970;52:95-8.

41. Pavel A, Smith RL, Ballard A, Larsen IJ. Prophylactic antibiotics in clean orthopaedic surgery. J Bone Joint Surg Am 1974;56:777-82.

42. Meehan J, Jamali AA, Nguyen H. Prophylactic antibiotics in hip and knee arthroplasty. J Bone Joint Surg Am 2009;91:2480-90. doi:10.2106/JBJS.H.01219.

43. Mauerhan DR, Nelson CL, Smith DL, Fitzgerald RH Jr, Slama TG, Petty RW, et al. Prophylaxis against infection in total joint arthroplasty. One day of cefuroxime compared with three days of cefazolin. J Bone Joint Surg Am 1994;76:39-45. 
44. Van Kasteren MEE, Manniën J, Ott A, Kullberg B-J, de Boer AS, Gyssens IC. Antibiotic prophylaxis and the risk of surgical site infections following total hip arthroplasty: timely administration is the most important factor. Clin Infect Dis Off Publ Infect Dis Soc Am 2007;44:921-7. doi:10.1086/512192.

45. Hansen E, Belden K, Silibovsky R, Vogt M, Arnold WV, Bicanic G, et al. Perioperative antibiotics. J Arthroplasty 2014;29:29-48. doi:10.1016/j.arth.2013.09.030.

46. Tanner J, Norrie P, Melen K. Preoperative hair removal to reduce surgical site infection. Cochrane Database Syst Rev 2011:CD004122. doi:10.1002/14651858.CD004122.pub4.

47. Lee J, Singletary R, Schmader K, Anderson DJ, Bolognesi M, Kaye KS. Surgical site infection in the elderly following orthopaedic surgery. Risk factors and outcomes. J Bone Joint Surg Am 2006;88:1705-12. doi:10.2106/JBJS.E.01156.

48. Prokuski L. Prophylactic antibiotics in orthopaedic surgery. J Am Acad Orthop Surg 2008;16:283-93.

49. Von Eiff C, Becker K, Machka K, Stammer H, Peters G. Nasal carriage as a source of Staphylococcus aureus bacteremia. Study Group. N Engl J Med 2001;344:11-6. doi:10.1056/NEJM200101043440102.

50. Edwards PS, Lipp A, Holmes A. Preoperative skin antiseptics for preventing surgical wound infections after clean surgery. Cochrane Database Syst Rev 2004:CD003949. doi:10.1002/14651858.CD003949.pub2.

51. Ostrander RV, Brage ME, Botte MJ. Bacterial skin contamination after surgical preparation in foot and ankle surgery. Clin Orthop 2003:246-52. doi:10.1097/01.blo.0000030176. 56585.d3.

52. Keblish DJ, Zurakowski D, Wilson MG, Chiodo CP. Preoperative skin preparation of the foot and ankle: bristles and alcohol are better. J Bone Joint Surg Am 2005;87:986-92. doi:10.2106/JBJS.D.02695.

53. Ostrander RV, Botte MJ, Brage ME. Efficacy of surgical preparation solutions in foot and ankle surgery. J Bone Joint Surg Am 2005;87:980-5. doi:10.2106/JBJS.D.01977.

54. Tanner J, Swarbrook S, Stuart J. Surgical hand antisepsis to reduce surgical site infection. Cochrane Database Syst Rev 2008:CD004288. doi:10.1002/14651858.CD004288.pub2.

55. Larson EL, Butz AM, Gullette DL, Laughon BA. Alcohol for surgical scrubbing? Infect Control Hosp Epidemiol Off J Soc Hosp Epidemiol Am 1990;11:139-43.

56. Katthagen $\mathrm{BD}$, Zamani $\mathrm{P}$, Jung W. [Effect of surgical draping on bacterial contamination in the surgical field]. $Z$ Für Orthop Ihre Grenzgeb 1992;130:230-5. doi:10.1055/ s-20081040144.

57. French ML, Eitzen HE, Ritter MA. The plastic surgical adhesive drape: an evaluation of its efficacy as a microbial barrier. Ann Surg 1976;184:46-50.

58. Johnston DH, Fairclough JA, Brown EM, Morris R. Rate of bacterial recolonization of the skin after preparation: four methods compared. Br J Surg 1987;74:64.

59. Blom AW, Gozzard C, Heal J, Bowker K, Estela CM. Bacterial strike-through of re-usable surgical drapes: the effect of different wetting agents. J Hosp Infect 2002;52:52-5.

60. Blom A, Estela C, Bowker K, MacGowan A, Hardy JR. The passage of bacteria through surgical drapes. Ann R Coll Surg Engl 2000;82:405-7.
61. Ritter MA, Campbell ED. Retrospective evaluation of an iodophor-incorporated antimicrobial plastic adhesive wound drape. Clin Orthop 1988:307-8.

62. Jacobson C, Osmon DR, Hanssen A, Trousdale RT, Pagnano MW, Pyrek J, et al. Prevention of wound contamination using DuraPrep solution plus Ioban 2 drapes. Clin Orthop 2005;439:32-7.

63. Webster J, Alghamdi AA. Use of plastic adhesive drapes during surgery for preventing surgical site infection. Cochrane Database Syst Rev 2007:CD006353. doi:10.1002/14651858.CD006353.pub2.

64. Alijanipour P, Karam J, Llinás A, Vince KG, Zalavras C, Austin M, et al. Operative environment. J Orthop Res Off Publ Orthop Res Soc 2014;32 Suppl 1:S60-80. doi:10.1002/ jor.22550.

65. Guo YP, Wong PM, Li Y, Or PPL. Is double-gloving really protective? A comparison between the glove perforation rate among perioperative nurses with single and double gloves during surgery. Am J Surg 2012;204:210-5. doi:10.1016/j.amjsurg.2011.08.017.

66. Tanner J, Parkinson H. Double gloving to reduce surgical cross-infection. Cochrane Database Syst Rev 2006:CD003087. doi:10.1002/14651858.CD003087.pub2.

67. Ersozlu S, Sahin O, Ozgur AF, Akkaya T, Tuncay C. Glove punctures in major and minor orthopaedic surgery with double gloving. Acta Orthop Belg 2007;73:760-4.

68. Carter AH, Casper DS, Parvizi J, Austin MS. A prospective analysis of glove perforation in primary and revision total hip and total knee arthroplasty. J Arthroplasty 2012;27:1271-5. doi:10.1016/j.arth.2012.01.021.

69. Demircay E, Unay K, Bilgili MG, Alataca G. Glove perforation in hip and knee arthroplasty. J Orthop Sci Off J Jpn Orthop Assoc 2010;15:790-4. doi:10.1007/ s00776-010-1547-0.

70. Sutton PM, Greene T, Howell FR. The protective effect of a cut-resistant glove liner: a prospective, randomised trial. J Bone Joint Surg Br 1998;80-B:411-3.

71. Pieper SP, Schimmele SR, Johnson JA, Harper JL. A prospective study of the efficacy of various gloving techniques in the application of Erich arch bars. J Oral Maxillofac Surg Off J Am Assoc Oral Maxillofac Surg 1995;53:1174-1176; discussion 1177.

72. Parvizi J, Saleh KJ, Ragland PS, Pour AE, Mont MA. Efficacy of antibiotic-impregnated cement in total hip replacement. Acta Orthop 2008;79:335-41. doi:10.1080/ 17453670710015229.

73. Engesaeter LB, Lie SA, Espehaug B, Furnes O, Vollset SE, Havelin LI. Antibiotic prophylaxis in total hip arthroplasty: effects of antibiotic prophylaxis systemically and in bone cement on the revision rate of 22,170 primary hip replacements followed 0-14 years in the Norwegian Arthroplasty Register. Acta Orthop Scand 2003;74:644-51. doi:10.1080/ 00016470310018135.

74. Bohm E, Zhu N, Gu J, de Guia N, Linton C, Anderson T, et al. Does adding antibiotics to cement reduce the need for early revision in total knee arthroplasty? Clin Orthop 2014;472:162-8. doi:10.1007/s11999-013-3186-1.

75. Namba RS, Inacio MCS, Paxton EW. Risk factors associated with deep surgical site infections after primary total knee arthroplasty: an analysis of 56,216 knees. J Bone Joint Surg Am 2013;95:775-82. doi:10.2106/JBJS.L.00211. 
76. Citak M, Argenson J-N, Masri B, Kendoff D, Springer B, Alt V, et al. Spacers. J Arthroplasty 2014;29:93-9. doi:10.1016/j.arth.2013.09.042.

77. Koval KJ, Rosenberg AD, Zuckerman JD, Aharonoff GB, Skovron ML, Bernstein RL, et al. Does blood transfusion increase the risk of infection after hip fracture? J Orthop Trauma 1997;11:260-265; discussion 265-266.

78. Innerhofer P, Klingler A, Klimmer C, Fries D, Nussbaumer W. Risk for postoperative infection after transfusion of white blood cell-filtered allogeneic or autologous blood components in orthopedic patients undergoing primary arthroplasty. Transfusion (Paris) 2005;45:103-10. doi:10.1111/j.1537-2995.2005.04149.x.

79. Spahn DR. Anemia and patient blood management in hip and knee surgery: a systematic review of the literature. Anesthesiology 2010;113:482-95. doi:10.1097/ ALN.0b013e3181e08e97.

80. Alshryda S, Sarda P, Sukeik M, Nargol A, Blenkinsopp J, Mason JM. Tranexamic acid in total knee replacement: a systematic review and meta-analysis. J Bone Joint Surg Br 2011;93:1577-85. doi:10.1302/0301-620X.93B12.26989.

81. Yang Z-G, Chen W-P, Wu L-D. Effectiveness and safety of tranexamic acid in reducing blood loss in total knee arthroplasty: a meta-analysis. J Bone Joint Surg Am 2012;94:1153-9. doi:10.2106/JBJS.K.00873.

82. Rasouli MR, Gomes LSM, Parsley B, Barsoum W, Bezwada $\mathrm{H}$, Cashman J, et al. Blood conservation. I Arthroplasty 2014;29:65-70. doi:10.1016/j.arth.2013.09.032.

83. Gastmeier P, Breier A-C, Brandt C. Influence of laminar airflow on prosthetic joint infections: a systematic review. J Hosp Infect 2012;81:73-8. doi:10.1016/j.jhin.2012.04.008.

84. Ong KL, Lau E, Manley M, Kurtz SM. Effect of procedure duration on total hip arthroplasty and total knee arthroplasty survivorship in the United States Medicare population. J Arthroplasty 2008;23:127-32. doi:10.1016/ j.arth.2008.04.022.

85. Urquhart DM, Hanna FS, Brennan SL, Wluka AE, Leder K, Cameron PA, et al. Incidence and risk factors for deep surgical site infection after primary total hip arthroplasty: a systematic review. J Arthroplasty 2010;25:1216-1222.e1-3. doi:10.1016/j.arth.2009.08.011.

86. Muilwijk J, van den Hof S, Wille JC. Associations between surgical site infection risk and hospital operation volume and surgeon operation volume among hospitals in the Dutch nosocomial infection surveillance network. Infect Control Hosp Epidemiol Off J Soc Hosp Epidemiol Am 2007;28:557-63. doi:10.1086/513613.
87. Andersson AE, Bergh I, Karlsson J, Eriksson BI, Nilsson K. Traffic flow in the operating room: an explorative and descriptive study on air quality during orthopedic trauma implant surgery. Am J Infect Control 2012;40:750-5. doi:10.1016/j.ajic.2011.09.015.

88. Salvati EA, Robinson RP, Zeno SM, Koslin BL, Brause BD, Wilson PD Jr. Infection rates after 3175 total hip and total knee replacements performed with and without a horizontal unidirectional filtered air-flow system. J Bone Joint Surg Am 1982;64:525-35.

89. Young RS, O'Regan DJ. Cardiac surgical theatre traffic: time for traffic calming measures? Interact Cardiovasc Thorac Surg 2010;10:526-9. doi:10.1510/icvts.2009.227116.

90. Davis N, Curry A, Gambhir AK, Panigrahi H, Walker CR, Wilkins EG, et al. Intraoperative bacterial contamination in operations for joint replacement. J Bone Joint Surg $\mathrm{Br}$ 1999;81:886-9.

91. Givissis P, Karataglis D, Antonarakos P, Symeonidis P, christodoulou A. Suction during orthopaedic surgery. How safe is the suction tip? ACTA ORTHOPÆDICA Belg 2008;74:531-3.

92. Greenough CG. An investigation into contamination of operative suction. J Bone Joint Surg Br 1986;68:151-3.

93. Insull PJ, Hudson J. Suction tip: a potential source of infection in clean orthopaedic procedures. ANZ J Surg 2012;82:185-6. doi:10.1111/j.1445-2197.2011.05949.x.

94. Mulcahy DM, McCormack D, McElwain JP. Intraoperative suction catheter tip contamination. $J$ R Coll Surg Edinb 1994;39:371-3.

95. Beldame J, Lagrave B, Lievain L, Lefebvre B, Frebourg N, Dujardin F. Surgical glove bacterial contamination and perforation during total hip arthroplasty implantation: when gloves should be changed. Orthop Traumatol Surg Res OTSR 2012;98:432-40. doi:10.1016/j.otsr.2011.10.015.

96. American Academy of Orthopedic Surgeons. AAOS clinical practice guideline: Prevention of orthopaedic implant infection in patients undergoing dental procedures n.d.

97. Chen A, Haddad F, Lachiewicz P, Bolognesi M, Cortes LE, Franceschini M, et al. Prevention of late PII. J Arthroplasty 2014;29:119-28. doi:10.1016/j.arth.2013.09.051.

This article is also available online on the SAOA website (www.saoa.org.za) and the SciELO website (www.scielo.org.za). Follow the directions on the Contents page of this journal to access it. 